\title{
Density-dependent growth and mortality in an estuary-dependent fish: an experimental approach with juvenile spot Leiostomus xanthurus
}

\author{
J. Kevin Craig ${ }^{1,5, *}$, James A. Rice ${ }^{2}$, Larry B. Crowder ${ }^{3}$, David A. Nadeau ${ }^{4}$ \\ ${ }^{1}$ Department of Zoology, Center for Marine Sciences and Technology, North Carolina State University, 303 College Circle, \\ Morehead City, North Carolina 28557, USA \\ ${ }^{2}$ Department of Zoology, North Carolina State University, Raleigh, North Carolina 27695-7617, USA \\ ${ }^{3}$ Nicholas School of the Environment and Earth Sciences, Duke Center for Marine Conservation, 135 Duke Marine Lab Rd., \\ Beaufort, North Carolina 28516-9721, USA \\ ${ }^{4}$ MarineLab, Marine Resources Development Foundation, 51 Shoreland Drive, Key Largo, Florida 33037, USA \\ ${ }^{5}$ Present address: Florida State University Coastal and Marine Laboratrory, 3618 Highway 98, St. Teresa, Florida 32358-2702, USA
}

\begin{abstract}
The abundance of demersal marine fishes is a function of both pre-settlement processes that influence recruitment to benthic juvenile habitats, as well as post-settlement density-dependent processes that act during the juvenile stage. Few studies have investigated density-dependence for fishes that spawn offshore and recruit to inshore estuaries for the juvenile stage prior to returning to offshore waters as adults (i.e. estuary-dependent). We conducted 2 replicated experiments at different spatial scales to test for density-dependent growth and mortality in juvenile spot Leiostomus xanthurus, a common estuary-dependent species. In the small-scale experiment, we stocked spot in $1 \mathrm{~m}^{2}$ cages in a marsh creek at densities of 2, 5, and 10 fish $\mathrm{m}^{-2}$ and determined their growth and mortality after $51 \mathrm{~d}$. In the large-scale experiment, we stocked spot in $79 \mathrm{~m}^{2}$ pond sections at 2, 5, and 10 fish $\mathrm{m}^{-2}$ and determined their growth and mortality after $52 \mathrm{~d}$. We sampled benthic infauna at the end of the pond experiment to determine if prey availability mediated the effects of density on spot growth and mortality. Average spot growth rates decreased 83 to $97 \%$ and mortality increased 2- to 4 -fold as density increased from 2 to 10 fish $\mathrm{m}^{-2}$. The density of benthic infauna at the end of the pond experiment was inversely related to spot density, consistent with competition for food as the underlying mechanism. Estimates of spot density compiled from the literature indicate that the density-dependent effects we observed occurred within the range of reported field densities. Our results provide strong experimental support for the hypothesis that density-dependent processes during the demersal juvenile stage in estuaries can modify patterns in the abundance of spot, and perhaps other estuary-dependent species, that are established prior to settlement.
\end{abstract}

KEY WORDS: Density-dependent growth · Density-dependent mortality · Spot · Leiostomus xanthurus $\cdot$ Estuarine nursery $\cdot$ Food limitation

\section{INTRODUCTION}

Density-dependence is a causal relationship between the density of organisms during a particular life stage and a per capita demographic rate that involves a positive or a negative feedback mechanism. A mechanistic understanding of density-dependence in fishes is important given the influence of density on individ- ual growth rates and population vital rates, such as mortality and reproduction, that ultimately regulate population size (Hixon et al. 2002). A common view is that variation in the abundance of marine fishes is generated primarily by density-independent processes during the egg and larval stage and then modified by density-dependent processes during the juvenile stage (Leggett \& DeBlois 1994). 
Several lines of evidence suggest that the juvenile stage may be particularly important in understanding the role of density-dependence in marine fish populations. First, the longer duration of the juvenile stage compared to the larval stage may compensate for typically lower juvenile mortality rates, such that processes affecting juveniles may contribute substantially to total cohort mortality (Sissenwine 1984). Second, population growth rates from stage-structured models of fishes that use estuaries during their first year of life are often highly sensitive to processes during the juvenile stage (e.g. Quinlan \& Crowder 1999). Third, densitydependent growth is probably most intense for early juveniles when fish density and population consumption rates are highest relative to prey density and production rates (Cowan et al. 2000). Depressed growth at high density can lead to increased mortality (Sogard 1997) and decreased reproductive output (Lorenzen \& Enberg 2002) when these processes are size-dependent. Fourth, density-dependent mortality during the demersal juvenile stage has been reported for several marine fishes (Myers \& Cadigan 1993), and is often associated with functional and numerical responses of predators to high densities of early post-settlement fishes (Hixon et al. 2002). Recent evidence suggests the mechanisms underlying densitydependence may be complex, however, and involve the interplay between competition, predation, larval supply, and resource dynamics that occur over multiple spatial and temporal scales (Hixon \& Jones 2005).

Little is known about the importance of densitydependent processes for fishes that are spawned offshore, use estuaries as nursery grounds during the juvenile stage, then return to offshore spawning grounds as adults (i.e. estuary-dependent). High mortality rates during the larval stage and variable transport processes from offshore spawning areas to inshore estuarine nursery habitats may result in juvenile densities below levels where density-dependence occurs. Alternatively, evidence for density-dependent loss rates (mortality and emigration) and growth rates during the juvenile stage has been reported for several species, indicating that density-dependent processes during estuarine residency can modify patterns in abundance established prior to settlement (Modin \& Pihl 1994, McBride et al. 1995, Buckel et al. 1999, Kimmerer et al. 2000, Scharf 2000). This question has taken on new importance due to growing concerns about habitat loss and degradation in nearshore coastal ecosystems that serve as juvenile nurseries (Beck et al. 2001). For example, hypoxia (dissolved oxygen $\leq 2.0 \mathrm{mg} \mathrm{l}^{-1}$ ) resulting from nutrient over-enrichment associated with anthropogenic activities in coastal watersheds is becoming more prevalent in estuaries (Diaz 2000). Hypoxia may decrease the productive capacity of estuarine habitats through direct mortality of benthic food resources important to demersal fishes (Powers et al. 2005) and through avoidance behaviors that crowd fishes into remaining oxygenated refuges (Eby et al. 2005), both of which may intensify densitydependent effects on growth and mortality.

Spot Leiostomus xanthurus is an important demersal species in the western Atlantic that uses estuaries as nurseries during its first year of life. Fish are spawned in offshore waters during winter (November to March) and recruit to shallow estuarine nursery creeks, with peak recruitment typically occurring in early spring (February to April; Weinstein 1979). Early post-settlement densities can be extremely high (30 to $100 \mathrm{~m}^{-2}$; Weinstein \& Brooks 1983, Rogers et al. 1984), whereas densities of larger juveniles during summer (June to August) are variable but can reach $>10$ fish $\mathrm{m}^{-2}$ (Weinstein 1979, Rozas \& Hackney 1984). Age-0 spot remain in nursery creeks for weeks to months (Weinstein et al. 1984), where they grow rapidly on a diverse benthic prey assemblage prior to moving to deeper estuarine and offshore waters (Hodson et al. 1981). Even though spot and other similar estuary-dependent species comprise a large portion of the demersal fish biomass in estuaries, little is known about the processes affecting growth and mortality rates during the juvenile stage.

In the present study, we report the results of 2 experiments designed to determine whether growth and mortality of Age- 0 juvenile spot are density-dependent. An experimental approach can provide a process-level understanding of how growth and mortality are related to density and avoids many of the problems that have been previously identified with the use of observational field data (e.g. Langton et al. 2002). However, experimental results may be sensitive to potential artifacts such as limitations on the size of experimental units that may constrain the spatial scale over which organisms can move. To help address the latter, we conducted similar experiments at 2 different spatial scales using $1 \mathrm{~m}^{2}$ field enclosures in an estuarine tidal creek and in relatively large sections $\left(79 \mathrm{~m}^{2}\right)$ of mud-bottom experimental ponds $\left(320 \mathrm{~m}^{2}\right)$. We compared the density of benthic infauna remaining at the end of the pond experiment among spot density treatments to determine if competition for food was responsible for the densitydependent effects we observed. In addition, we compared alternative statistical models derived from our experimental results to determine the functional relationship between spot density and growth rate. Finally, we compiled field estimates of Age- 0 juvenile spot densities from a variety of estuarine habitats and sampling methods to compare the densities at which effects on growth and mortality occurred in our experiments with those observed in the field. Collectively, our analysis provides strong experimental evidence for density- 
dependent growth and mortality within the range of commonly reported densities of juvenile spot in estuaries, and highlights the potential importance of these processes during the juvenile stage in driving the population dynamics of estuary-dependent fishes.

\section{MATERIALS AND METHODS}

Field enclosure experiment. The first experiment was conducted in a shallow (maximum depth $2 \mathrm{~m}$ ) marsh creek that typically supports high densities of juvenile spot (Prytherch's Pond, Pivers Island, North Carolina, USA). Tidal exchange within the creek results in relatively moderate bottom temperature and dissolved oxygen conditions (daily means, July to September: temperature, 28.9 to $29.5^{\circ} \mathrm{C}$ i dissolved oxygen, 6.0 to $6.7 \mathrm{mg} \mathrm{l}^{-1}$; Yip-Hoi 2003). Spot were collected using seine nets from local waters, held in flowthrough tanks for several days, and fed commercial fish pellets. Cylindrical enclosures $\left(1.0 \mathrm{~m}^{2}\right.$ basal area, $1.2 \mathrm{~m}$ high) were constructed of $0.63 \mathrm{~cm}$ vexar plastic mesh attached to $2.5 \mathrm{~cm}$ (inside diameter) flexible PVC tubing and enclosed on the top and bottom. Mud from the creek bottom was added to a depth of 3 to $5 \mathrm{~cm}$ in each enclosure and left undisturbed for $1 \mathrm{wk}$ to provide a natural substrate. Spot were individually weighed (3 to $5 \mathrm{~g}$ wet weight) prior to stocking into 18 field enclosures at treatment densities of 2,5, and $10 \mathrm{fish} \mathrm{m}^{-2}$ in a randomized block design. Treatments were randomly assigned to 1 of 3 cages in each of 6 blocks ( 6 replicates per treatment) distributed along a $20 \mathrm{~m}$ stretch of the north and south shores of the creek at approximately the same water depth $(1.5 \mathrm{~m})$. There was no difference in the mean initial weight of spot among density treatments $\left(F_{2,94}=0.446, \mathrm{p}=0.64\right)$ or among blocks $\left(F_{5,94}=\right.$ $0.368, \mathrm{p}=0.87$ ). The experiment ran for $51 \mathrm{~d}$ (23 July to 12 September 1993), after which the number, individual weight, and standard length (SL) of surviving spot were recorded.

We calculated specific growth rate $(g)$ as the difference in the natural log of mean final and mean initial weight in each replicate divided by the experiment duration $(51 \mathrm{~d}) ; g$ was converted to daily weight specific growth rate $\left(g^{-1} \mathrm{~d}^{-1}\right)$ as $1-\mathrm{e}^{-g}$ (Ricker 1975). To allow for comparison with the pond experiment (below), we also calculated the average daily growth in length as the difference between the mean final and mean initial SL of spot in each replicate divided by the experiment duration. Initial lengths were converted from initial weights using a length-weight relationship and ranged from 52 to $60 \mathrm{~mm}(\mathrm{SL}=37.273 \times$ weight $^{0.2994} ; \mathrm{n}=85 ; \mathrm{R}^{2}=0.98 ;$ J. A. Rice \& J. K. Craig unpubl. data). We calculated the average relative condition factor $(K)$ of surviving spot in each replicate as an index of fish condition $\left(K=W / W_{\mathrm{p}}\right.$, where $W$ is the measured average weight of surviving fish and $W_{\mathrm{p}}$ is the weight predicted from the length-weight relationship above; Anderson \& Gutreuter 1983).

Pond experiment. The second experiment was conducted in 2 shallow, mud-bottom experimental ponds (320 $\mathrm{m}^{2}$ each, $1 \mathrm{~m}$ maximum depth, Morehead City, North Carolina, USA) over 52 d (7 June to 29 July 1994) at the same densities as above. Fish collection and holding procedures were the same as for the field enclosure experiment. Each pond was divided into 4 pie-wedge sections by burying plastic $0.63 \mathrm{~cm}$ vexar mesh fences attached to supporting stakes $20 \mathrm{~cm}$ into the substrate. A circular fence was constructed around the center standpipe to eliminate sharp corners. The area of each section was estimated (nearest $\mathrm{m}^{2}$ ) by measuring from the fence around the center standpipe to the water edge at $1 \mathrm{~m}$ intervals, transferring these measurements to graph paper, and counting the number of full and partial squares contained within each section. Section areas ranged from 71 to $88 \mathrm{~m}^{2}$ (mean $\left.=79 \mathrm{~m}^{2}\right)$. Mesh netting was placed over both ponds $1 \mathrm{~m}$ above the water surface and staked to the ground along the shoreline to prevent bird predation. The initially empty ponds were filled with natural seawater (31 to $35 \mathrm{ppt}$ ) pumped continuously from adjacent Bogue Sound through a small intake and drained through the center standpipe. The ponds were filled about 1 mo prior to stocking spot to allow colonization by the naturally occurring benthic prey assemblage. A vexar mesh bag (double layers of $0.25 \mathrm{~cm}$ mesh) was placed over the water intake to prevent colonization by larger aquatic organisms.

Density treatments of 2, 5, and 10 fish $\mathrm{m}^{-2}$ were assigned randomly to 3 of the sections within each pond ( 2 replicates per treatment) in a randomized block design; the fourth section of each pond was not stocked. Stocking took place over a $7 \mathrm{~d}$ period (7 June to 13 June), with most of the fish stocked on Day 1 (65\%) followed by Day $3(25 \%)$ and Day 7 (10\%). All pond sections were stocked simultaneously with small batches of fish added to each section repeatedly on each day of the stocking period until target densities were attained. To minimize handling large numbers of fish, only a subsample of each batch was measured for $\mathrm{SL}$ prior to stocking (mean $\pm \mathrm{SD} ; 40.3 \pm 8.5 \mathrm{~mm} \mathrm{SL}$; $\mathrm{n}=86$ ). The minimum and maximum daily temperatures $\left(25\right.$ to $\left.38^{\circ} \mathrm{C}\right)$ in the ponds were recorded on 12 dates during the experiment with a min.-max. thermometer. Salinity (35 to $38 \mathrm{ppt}$ ) was measured with a refractometer at the header tank supplying the ponds on 10 dates.

After $52 \mathrm{~d}$, the ponds were seined and drained, all surviving spot counted, and a subsample of 100 fish from each replicate measured for SL. Average linear growth rate was estimated as the difference between 
the mean SL of spot in each replicate at the end of the experiment and the subsample of spot measured at the beginning of the experiment divided by the experiment duration.

To determine if the abundance of benthic infauna at the end of the pond experiment differed among spot density treatments, we collected 10 sediment cores (3.8 $\mathrm{cm}$ diameter $\times 4 \mathrm{~cm}$ deep) from randomly selected locations in each of the 4 sections in each pond (the 3 spot density treatments and the 1 unstocked section). The sediment from the 10 cores per replicate was pooled and re-suspended in fresh water to separate organisms by flotation. The supernatant was strained and brought to a volume of $250 \mathrm{ml}$ with fresh water. The remaining sediment was examined directly for any remaining organisms and sediment volume measured by the amount of water displaced $\left(\sim 400 \mathrm{~cm}^{3}\right.$ total sediment per sample). Two $5 \mathrm{ml}$ subsamples were taken from the supernatant with a Stempel pipet, and all organisms identified to major taxonomic groups and counted under a dissecting microscope at 40× magnification. The density of each group (no. $\mathrm{cm}^{-3}$ ) was estimated by extrapolating to the total sample volume and dividing by the volume of sediment sampled.

Statistical analyses. In preliminary analyses, 3 alternative metrics of fish density-numerical density $\left(\Sigma \mathrm{SL}^{0}\right)$, effective density $\left(\Sigma \mathrm{SL}^{2}\right)$, and biomass density $\left(\Sigma \mathrm{SL}^{3}\right)$ (Walters \& Post 1993) - gave similar results; we used numerical density in all analyses reported here. For both experiments, we tested for differences in mortality and growth rates of spot among density treatments using a randomized block ANOVA followed by Bonferroni-corrected pairwise comparisons (Zar 1996). Percent spot mortality was arcsine square-root transformed prior to analysis.

We tested for growth depensation, an increase in growth rate variation among individuals at high density and presumably more intense intraspecific competition (Ricker 1975). We calculated the difference in the coefficient of variation $(\mathrm{CV})$ in weight within each replicate between the end and the beginning of the field enclosure experiment and compared this difference among density treatments. We predicted that high-density replicates would show a greater difference between the beginning and end CV than lowdensity replicates. We could not test for growth depensation in the pond experiment because only a single initial length distribution (pooled over replicates) was available and final lengths were subsampled.

To determine if density-dependent effects were driven by competition for food resources, we compared the density of benthic infauna remaining at the end of the pond experiment with spot density using nonlinear regression. We averaged the densities of each benthic infauna taxonomic group between the 2 subsamples in each replicate prior to analysis. We also created a pooled group of 'key' benthic prey species commonly reported in spot diets that comprised harpacticoid copepods, copepod nauplii, polychaetes, and ostracods (Stickney et al. 1975, Sheridan 1979, Hodson et al. 1981). For the independent variable in these regressions (i.e. spot density) we used the projected density for each replicate midway through the experiment calculated from the exponential mortality coefficient ( $Z$; Ricker 1975). We tested the prediction that final infaunal density was negatively related to spot density by testing for a negative slope ( $\beta, 1$-tailed $t$-test) in a model of the form, infauna density $=\alpha \times$ $\mathrm{e}^{(\beta \times \text { spot density) }}$, where $\alpha$ and $\beta$ are fitted parameters.

To determine the functional relationship between spot growth rate and spot density, we compared alternative linear and nonlinear models for both the field enclosure experiment and the pond experiment. The linear model was of the form, growth rate $=\alpha+\beta \times$ density, and the nonlinear model was an exponential curve of the form, growth rate $=\alpha \times \mathrm{e}^{(\beta \times \text { density })}$. The independent variable in these regressions was the projected density midway through the experiment calculated as above. We used an information-theoretic approach based on Akaike information criteria (AIC) corrected for small sample size $\left(\mathrm{AIC}_{\mathrm{C}}\right)$ to select between the linear and nonlinear models (Burnham \& Anderson 2002). We computed Akaike weights and evidence ratios from $\mathrm{AIC}_{\mathrm{C}}$ to provide a measure of confidence in each of the models considered expressed as a probability that a particular model was the best approximating model in the set. All statistical analyses were done in Systat v8.0.

\section{RESULTS}

\section{Field enclosure experiment}

Spot mortality increased from 8 to $35 \%$ with increasing spot density over the 3 treatments (Fig. 1A; density: $F_{2,10}=7.23, \mathrm{p}=0.01$; block: $F_{5,10}=0.64, \mathrm{p}=0.67$ ). All spot survived the duration of the experiment in the 2 fish $\mathrm{m}^{-2}$ treatment with the exception of a single fish, while some mortality occurred in each of the 5 and 10 fish $\mathrm{m}^{-2}$ replicates. Mortality did not differ between the 5 and 10 fish $\mathrm{m}^{-2}$ treatments $(\mathrm{p}>0.9)$, but both experienced about 4 times the mortality observed in the 2 fish $\mathrm{m}^{-2}$ treatment (both $\mathrm{p}<0.03$ ).

Spot growth rates ranged from -0.01 to $0.36 \mathrm{~mm} \mathrm{~d}^{-1}$ or -0.10 to $1.9 \%$ body weight $d^{-1}$. Average growth in length decreased with increasing density over the 3 treatments

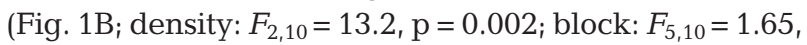
$\mathrm{p}=0.24)$. Growth of spot at 10 fish $\mathrm{m}^{-2}$ was depressed relative to that at both of the 2 lower densities (both $\mathrm{p}<$ 

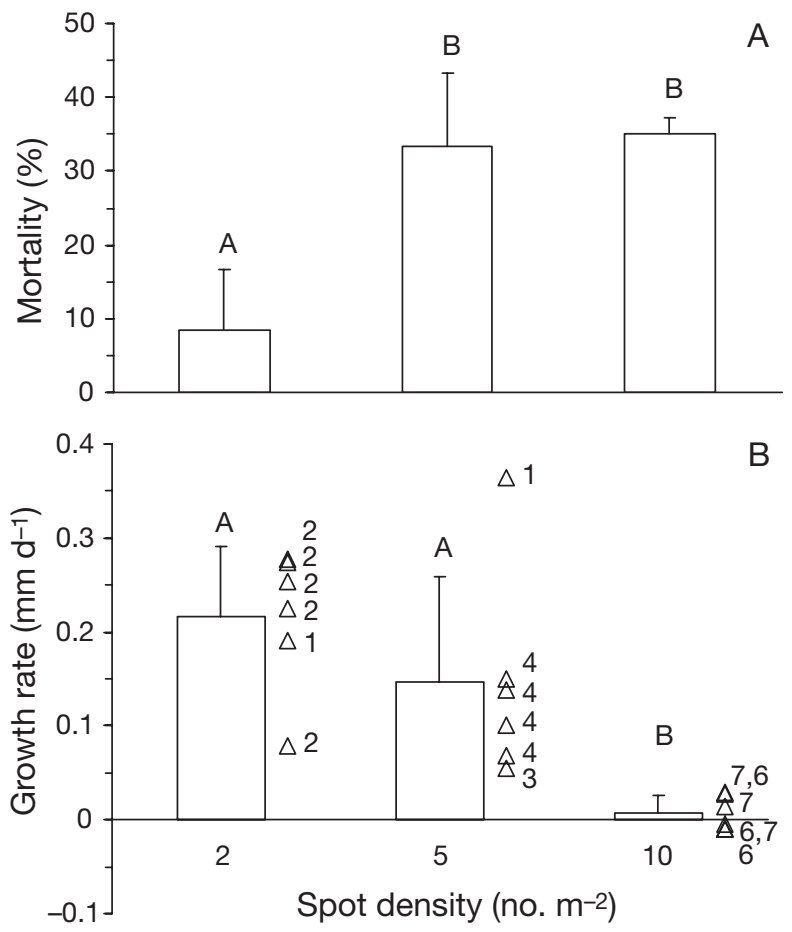

Fig. 1. Leiostomus xanthurus. Mean + SE (A) mortality and (B) growth of spot in the field enclosure experiment; different letters above error bars denote statistically significant differences $(p \leq 0.05) . \Delta$ average growth rates of individual replicates, numbers beside triangles $=$ final spot density in each replicate

0.022). The difference in growth rate between the 2 and 5 fish $\mathrm{m}^{-2}$ treatments was not statistically significant $(\mathrm{p}=$ 0.35 ), even though spot held at 2 fish $\mathrm{m}^{-2}$ grew about $49 \%$ faster on average than those held at 5 fish $\mathrm{m}^{-2}$. This was due to one outlying replicate, for which mortality was high and growth of the single surviving spot was $>3$-fold the average growth of the other replicates (Fig. 1B, p = 0.014 after removing outlier). Results were near identical based on specific growth in weight (density: $F_{2,10}=12.2, \mathrm{p}=0.002$; block: $F_{5,10}=1.61, \mathrm{p}=0.24$; 10 vs. 2 fish $\mathrm{m}^{-2}: \mathrm{p}=0.002 ; 10$ vs. 5 fish $\mathrm{m}^{-2}: \mathrm{p}=0.03 ; 5$ vs. 2 fish $\mathrm{m}^{-2}: \mathrm{p}=0.40$; after removing outlier: $\mathrm{p}=0.02$ ).

The CV in weight within individual replicates ranged from 2.3 to $22.4 \%$ at the beginning of the experiment and from 6.7 to $31.5 \%$ at the end of the experiment. There was no difference in initial CV among treatments (density: $F_{2,8}=2.15, \mathrm{p}=0.18$; block: $F_{5,8}=0.935, \mathrm{p}=$ 0.51). The CV of individual replicates tended to decrease from the beginning to the end of the experiment in the 2 fish $\mathrm{m}^{-2}$ treatments but tended to increase from the beginning to the end of the experiment in the 5 and 10 fish $\mathrm{m}^{-2}$ treatments (Fig. 2 ; density: $F_{2,8}=4.79, \mathrm{p}=$ 0.04 ; block: $F_{5,8}=0.15, \mathrm{p}=0.97$ ). There was no difference in relative condition factor $(K)$ of fish among density treatments at the end of the experiment (density: $F_{2,10}=1.19, \mathrm{p}=0.35$; block: $\left.F_{5,10}=0.88, \mathrm{p}=0.53\right)$.

\section{Pond experiment}

Spot mortality increased from 21.8 to $48.2 \%$ with increasing density over the 3 treatments (Fig. 3A; density: $F_{2,2}=23.17, \mathrm{p}=0.04$; block: $\left.F_{1,2}=0.09, \mathrm{p}=0.80\right)$. Differences in mortality between the 2 and 10 fish $\mathrm{m}^{-2}$

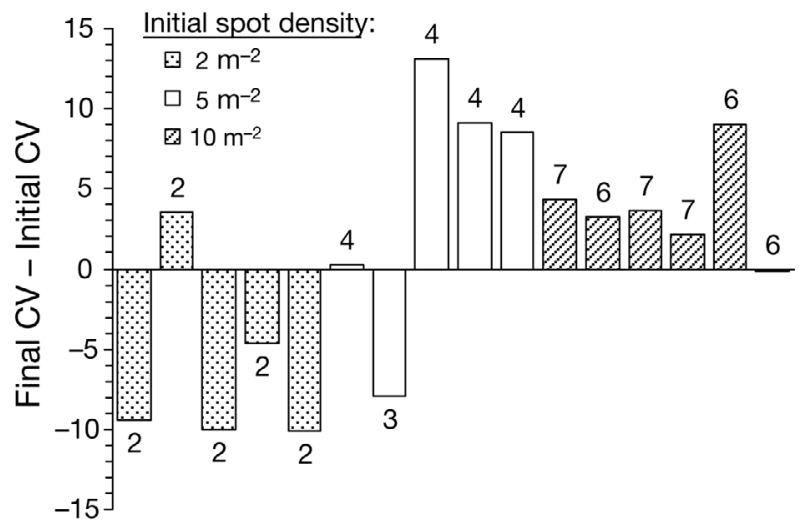

Fig. 2. Leiostomus xanthurus. Difference between final and initial coefficient of variation $(\mathrm{CV})$ in weight of each replicate of the field enclosure experiment (16 replicates with $>1$ surviving spot). Numbers $=$ final spot density in each replicate
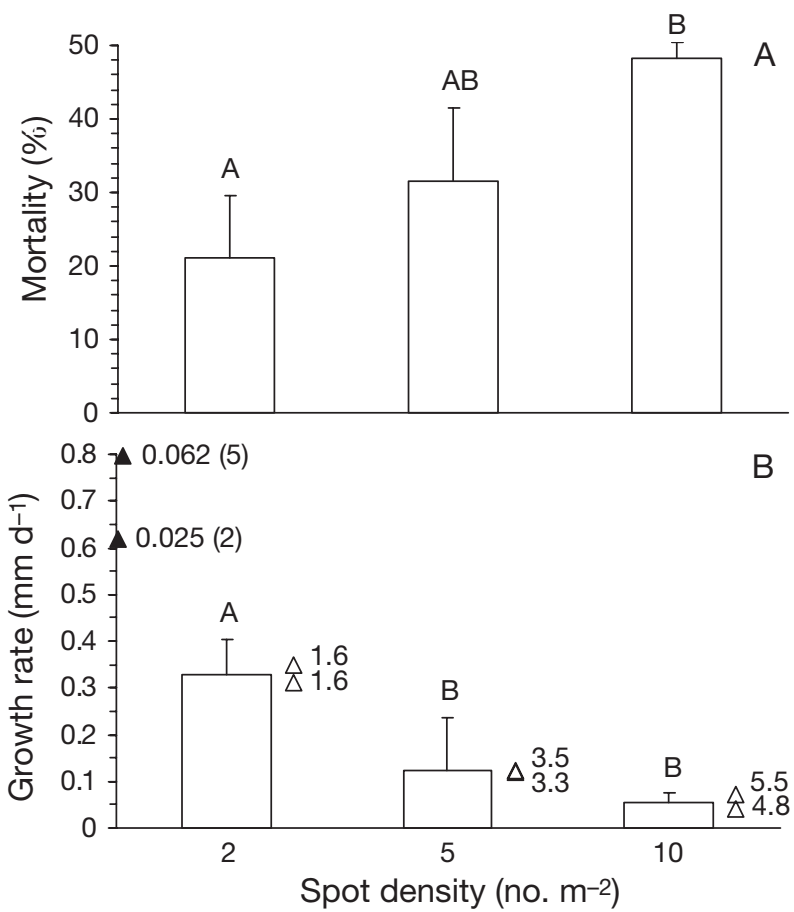

Fig. 3. Leiostomus xanthurus. Mean + SE (A) mortality and (B) growth of spot in the pond experiment; different letters above error bars denote statistically significant differences $(p \leq 0.05)$. $\Delta$ : average growth rates of individual treatment replicates; numbers beside triangles $=$ final spot density in each replicate;

$\boldsymbol{\Delta}$ : average growth rates of spot recovered from the 2 unstocked pond sections (number of fish recovered in parentheses) 
treatments were significant, while mortality in the 5 fish $\mathrm{m}^{-2}$ treatment was intermediate to, but not statistically different from, that of either 10 or 2 fish $\mathrm{m}^{-2}$ (both $\mathrm{p}>0.17$ ).

Average growth rates of spot in the pond experiment were similar to those in the field enclosure experiment, ranging from 0.04 to $0.35 \mathrm{~mm} \mathrm{~d}^{-1}$ or about 0.1 to $2.2 \%$ body weight $\mathrm{d}^{-1}$. Growth rate of spot in the pond experiment also decreased with increasing spot den-

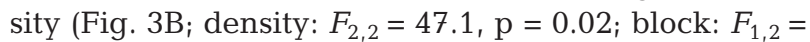
$0.09, \mathrm{p}=0.80$ ); average growth rate of spot at 2 fish $\mathrm{m}^{-2}$ was 2.7 -fold that at 5 fish $\mathrm{m}^{-2}(\mathrm{p}=0.04)$ and 6 -fold that at 10 fish $^{-2}(\mathrm{p}=0.02)$.

At the end of the pond experiment, 7 of the initial 2627 spot $(0.27 \%)$ were recovered from the 2 unstocked control sections of the 2 ponds $(5$ spot in the unstocked section of one pond and 2 spot in the unstocked section of the second pond; Fig. 3B). These fish could not have recruited through the water system during the experiment given their final sizes (58 to $93 \mathrm{~mm}$ ), but were more likely inadvertently placed in or escaped to the unstocked section in each pond. Despite the uncertain origins of these few fish, they provide valuable preliminary information on growth at extremely low densities. Assuming that these fish occupied the 2 control pond sections for the duration of the experiment (a conservative assumption because growth is spread over the maximum possible duration) and were initially similar to the average length of all stocked fish, growth rates were 88 and $142 \%$ faster than the average growth rate in the 2 fish $\mathrm{m}^{-2}$ treatment (Fig. 3B). Even assuming a much larger initial size such as the upper 95th percentile of the initial spot SL distribution (i.e. $55 \mathrm{~mm}$, a highly conservative assumption) growth was 2 and
$56 \%$ faster than the average growth rate in the 2 fish $\mathrm{m}^{-2}$ treatment.

Benthic infauna from sediment cores collected at the end of the pond experiment were numerically dominated by nematodes (93\%), followed by harpacticoid copepods $(2 \%)$, polychaetes $(1.4 \%)$, foraminiferans $(1.4 \%)$, ostracods $(0.74 \%)$, and copepod nauplii $(0.4 \%)$ (Fig. 4). Densities of the key taxonomic groups at the end of the experiment exhibited significant (copepods, polychaetes, ostracods) or marginally insignificant (nauplii, $\mathrm{p}=0.06$ ) declines in density with increasing spot density (Fig. 4A-D). For example, copepod density declined by about $80 \%$ between spot densities of 0 and 10 fish $\mathrm{m}^{-2}$ (Fig. 4A). When the key benthic infaunal groups were pooled, spot density explained $89 \%$ of the variation in benthic infauna density (Fig. 4E). The effect of spot density on the density of nematodes was marginally insignificant (Fig. 4F, p = 0.09), while there was no relationship between spot density and that of foraminiferans or miscellaneous species (unidentified or rare) (Fig. 4G,H).

\section{Functional relationship between spot density and growth rate}

Both linear and nonlinear (exponential) relationships between spot density and growth rate were supported by the data from the field enclosure experiment (Table 1, Fig. 5). The linear model had the lowest $\mathrm{AIC}_{\mathrm{c}}$ but had only a slightly greater probability than the exponential model (Akaike weight $=0.53$ vs. 0.47 ), indicating there was substantial evidence supporting both models. In contrast, the exponential model was clearly the better model in the pond experiment, with considerably less

Table 1. Leiostomus xanthurus. Model selection results for linear (growth $=\alpha+\beta \times$ density) and nonlinear (growth $=\alpha \times$ $\left.\mathrm{e}^{(\beta \times \text { density) }}\right)$ models of functional relationship between spot growth rate $\left(\mathrm{mm} \mathrm{d}^{-1}\right)$ and density. For the pond experiment, models were compared including $(n=8)$ and excluding $(n=6)$ the 2 'control' pond sections inadvertently containing 2 and 5 individual spot, respectively. $\alpha$ and $\beta$ are mean (SE) parameter estimates for each model and $\mathrm{n}$ is number of replicates

\begin{tabular}{|c|c|c|c|c|c|c|c|}
\hline $\begin{array}{l}\text { Expt, } \\
\text { Model }\end{array}$ & $\mathrm{n}$ & $\mathrm{AIC}_{\mathrm{c}}$ & $\Delta \mathrm{AIC}_{\mathrm{c}}$ & $\begin{array}{l}\text { Akaike } \\
\text { weight }\end{array}$ & $\begin{array}{l}\text { Evidence } \\
\text { ratio }\end{array}$ & $\alpha$ & $\beta$ \\
\hline \multicolumn{8}{|c|}{ Field enclosure } \\
\hline Linear & 18 & -35.6 & & 0.5267 & a & $0.291(0.03)$ & $-0.036(0.006)$ \\
\hline Nonlinear & 18 & -35.3 & 0.21 & 0.4733 & $1.11^{\mathrm{b}}$ & $0.445(0.11)$ & $-0.340(0.099)$ \\
\hline \multicolumn{8}{|l|}{ Pond } \\
\hline Linear & 8 & -2.80 & 5.90 & 0.0496 & $19.1^{\mathrm{c}}$ & $0.586(0.077)$ & $-0.086(0.018)$ \\
\hline Nonlinear & 8 & -8.70 & & 0.9504 & $\mathrm{a}$ & $0.719(0.042)$ & $-0.426(0.056)$ \\
\hline Linear & 6 & 2.00 & 4.61 & 0.0906 & $10.1^{\mathrm{c}}$ & $0.382(0.051)$ & $-0.049(0.011)$ \\
\hline Nonlinear & 6 & -2.61 & & 0.9094 & a & $0.653(0.074)$ & $-0.389(0.047)$ \\
\hline $\begin{array}{l}\text { a Best approx } \\
{ }^{\mathrm{b}} \text { Alternative } \\
{ }^{\mathrm{c}} \text { Alternative }\end{array}$ & $\begin{array}{l}\text { mo } \\
\text { wit }\end{array}$ & $\begin{array}{l}\text { vest AIC } \\
\text { antial ev } \\
\text { lerably } 1\end{array}$ & $\begin{array}{l}\text { ng those } \\
\text { of supp } \\
\text { idence o }\end{array}$ & $\begin{array}{l}\text { ared } \\
\left.\mathrm{IC}_{\mathrm{c}}<2\right) \\
\operatorname{prt}(\Delta \mathrm{AIC}\end{array}$ & & & \\
\hline
\end{tabular}



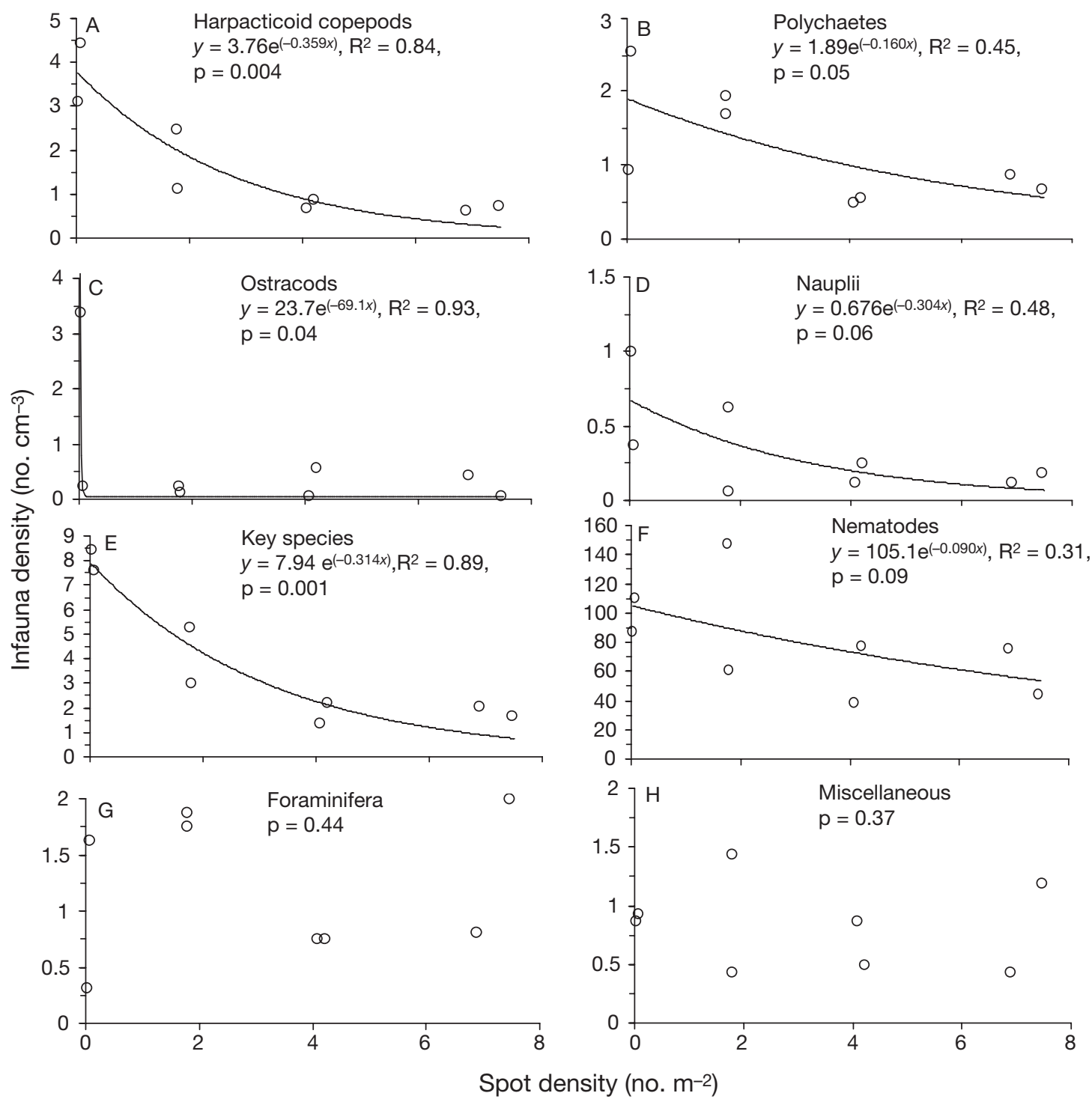

Fig. 4. Densities of benthic infauna from cores collected from spot Leiostomus xanthurus density treatments at the end of the pond experiment plotted against projected spot density midway through the experiment (see 'Materials and methods'). (A) to (D) are the common prey pooled as 'key species' in (E). Curves denote statistically significant $(\mathrm{p}<0.05)$ or marginally insignificant $(p<0.1)$ relationships. Note differences in scales of $y$-axes

evidence in support of the linear model (Table 1). Predicted growth at near zero density extrapolated from the exponential model (based on the original replicates) was similar to that observed in the few fish recovered from control sections $\left(<0.1\right.$ fish $\left.\mathrm{m}^{-2}\right)$, suggesting that these fish were growing at near maximal rates (Fig. 5).

\section{DISCUSSION}

We found strong experimental evidence for densitydependence in juvenile spot, with growth declining from 83 to $97 \%$ and mortality increasing 2 - to 4 -fold

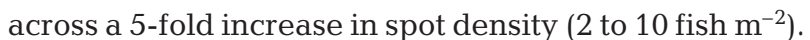
Our results were consistent between 2 independent experiments (mud-bottom ponds and field enclosures) with different potential artifacts and differing by nearly 2 orders of magnitude in spatial scale. Average daily growth rates of spot in the field enclosure experiment ( 0 to $0.25 \mathrm{~mm} \mathrm{~d}^{-1}$ ) were similar to those in the pond experiment ( 0 to $0.33 \mathrm{~mm} \mathrm{~d}^{-1}$ ) and both compared reasonably well to reported late spring and summer growth rates of juvenile spot in the field $\left(0.16\right.$ to $0.43 \mathrm{~mm} \mathrm{~d}^{-1}$; Ross 2003). In a separate experiment in the same ponds, however, average growth rates of juvenile spot provided with supplementary food (0.65 to $0.72 \mathrm{~mm} \mathrm{~d}^{-1}$; 


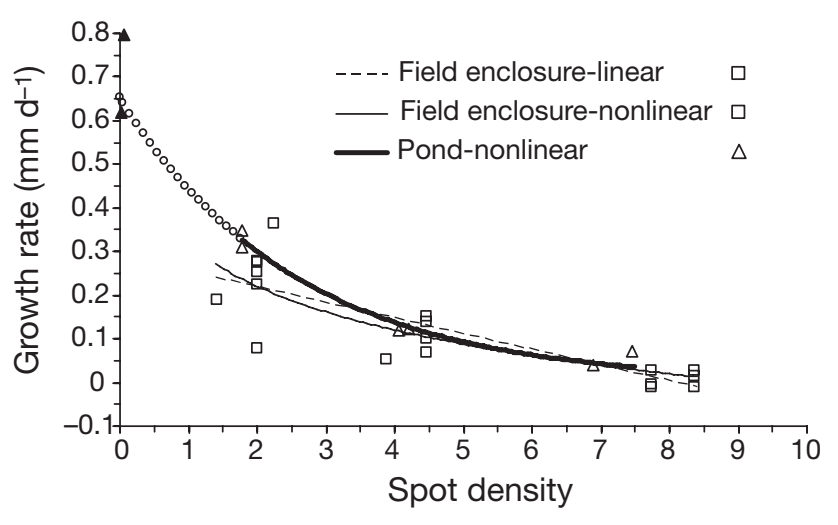

Fig. 5. Leiostomus xanthurus. Functional relationships between spot density and growth rate in the field enclosure and pond experiments. Curves show relationships for the best approximating model as well as alternative models with substantial evidence of support (evidence ratio $<2$, see Table 1). O: growth rates extrapolated to zero density based on exponential model applied to original 6 replicates of pond experiment. $\mathbf{\Delta}$ : average estimated growth rates of spot in control pond sections that experienced low densities $\left(<0.1\right.$ fish $\mathrm{m}^{-2}$; not used in model fits shown here)

Craig et al. 2006) were 2- to 3 -fold the maximum average growth rates for replicates of the current experiment ( 0.31 to $0.35 \mathrm{~mm} \mathrm{~d}^{-1}$; Fig. 3B) and similar to inferred growth rates of the few spot recovered from control sections where densities were extremely low (0.62 to $0.80 \mathrm{~mm} \mathrm{~d}^{-1}$; Fig. 3B). Growth rates estimated from the recapture of marked juvenile spot over 1 to $11 \mathrm{~d}$ in an estuarine tidal creek were also rapid in many cases, although highly variable $\left(-0.21\right.$ to $1.21 \mathrm{~mm} \mathrm{~d}^{-1}$; Weinstein et al. 1984). Highly variable growth rate below the physiological maximum given the constraints of body size and water temperature is consistent with the hypothesis that availability of food resources imposes limits on growth of juvenile spot in the field.

Several lines of evidence indicate that competition for food was an important process underlying densitydependent growth in our experiments. First, a number of infaunal prey that are commonly found in the diets of spot showed declining trends in abundance with increasing spot density by the end of the experiment, and this inverse relationship was strongest for harpacticoid copepods, a preferred prey that is an important component of juvenile spot diets in the field (Stickney et al. 1975). These results are probably conservative because our cores integrated prey densities over a deeper sediment depth $(\sim 4 \mathrm{~cm})$ than that over which spot are likely to forage $(<0.5 \mathrm{~cm})$, making spot density effects more difficult to detect. In contrast, densities of other prey showed no (i.e. foraminiferans) or only weak (i.e. nematodes) relationships to spot density. Second, the greater increase in relative size variation over time (i.e. growth depensation, Ricker 1975) in the high-density compared to the low-density treatments of the field enclosure experiment suggests that differences in growth rate among individual spot were amplified at high density. Growth depensation is often associated with asymmetric competition such that some individuals obtain more food resources or have lower metabolic costs than others, and has been reported in prior studies of density-dependent growth in fishes (Rubenstein 1981, Jenkins et al. 1999). Third, the exponentially declining relationship between spot growth rate and spot density is consistent with competition for a limiting resource. Such a relationship is thought to occur when organisms consume a larger fraction of available prey resources and possibly include less profitable prey items in their diet at higher densities (Jenkins et al. 1999), suggesting that the density-dependent effects that we observed were mediated by lower consumption rates, consumption of less energetically rich prey, or both. Another field enclosure experiment also reported density-dependent growth of Atlantic croaker Micropogonias undulatus, a similar estuary-dependent species, across a comparable range of densities to those used here (Eby et al. 2005), suggesting that density-dependent growth during the juvenile stage in estuaries may be important for other species as well.

The mechanism underlying density-dependent mortality in our experiments is unknown, but we suspect it is also associated with food limitation. In predator-free controls of a similar pond experiment at intermediate densities $\left(\sim 3\right.$ spot $\left.\mathrm{m}^{-2}\right)$ to those used here (2 to 5 spot $\mathrm{m}^{-2}$ ), mortality was higher for spot fed low rations that grew slowly compared to spot fed high rations that grew rapidly, suggesting that food limitation can lead to increased mortality even in the absence of predators (Craig et al. 2006, see also Rubenstein 1981, Forrester $\&$ Steele 2000). One possibility is that agonistic interactions among spot were intensified when densities were high and food resources limited. Two confamilial species (Atlantic croaker and black drum Pogonias cromis) establish dominance hierarchies and aggressively interact when food is limited, supporting this possibility (Gibbard et al. 1979). A second possibility is that food limitation at high densities led to decreased metabolic scope and increased susceptibility to physiological stress from abiotic factors. While high temperatures occasionally occurred in the ponds $\left(37.5^{\circ} \mathrm{C}\right)$, they persisted for only brief periods of time $\left(<1 \mathrm{~h} \mathrm{~d}^{-1}\right.$, Craig et al. 2006), making this possibility less likely. We also found no overt signs of disease, parasitism, or poor nutritional condition at the end of the experiments that might result from severe food limitation. Even so, the implication that density-dependent growth and mortality are both related to competition for food resources suggests a common underlying mechanism. 
Density-dependent mortality did not confound the effects of density on spot growth rates because the rank order of the treatment densities was maintained from the beginning to the end of the experiments. In fact, this makes our analysis conservative because (1) the density-dependent growth that we observed actually occurred at lower densities than those initially stocked (due to mortality), and (2) density-dependent mortality tended to decrease the relative differences in density among treatment levels from the beginning (5-fold range) to the end (3- to 4 -fold range) of the experiments, diminishing our statistical power to detect treatment effects.

Few studies have demonstrated density-dependent mortality due solely to competition (Hixon \& Jones 2005). Rather, predation arising from the functional and numerical responses of predators to high densities of juvenile fishes is thought to be a major source of densitydependent mortality in the field (van der Veer 1986, Hixon et al. 2002). In pond experiments similar to those reported here, consumption rates of Age- 0 spot by southern flounder Paralichthys lethostigma increased with increasing spot density and were similar to estimated field mortality rates (Wright et al. 1993), suggesting that flounder predation may be an important source of density-dependent mortality for juvenile spot in the wild. Since flounder and other predators were excluded from our experiments, however, we conclude that competition may also contribute directly to density-dependent mortality. Hixon \& Jones (2005) emphasized the interplay of competition and predation in relation to resources and larval supply as important factors underlying density-dependent mortality in demersal marine fishes, and suggested that the importance of competition (relative to predation) may have been underestimated. Perhaps flounder and other predators maintain the densities of juvenile spot in the field below levels at which competition is important. This is not supported by our pond data, however, which indicates that there is essentially no apparent low-density threshold below which competition has no effect. Density-dependent growth rates due to competition for food may extend the period over which spot are vulnerable to size-dependent predation (Sogard 1997). Consistent with this possibility, juvenile spot provided with limited food resources in a separate pond experiment grew more slowly and experienced higher sizedependent predation mortality from flounder than did spot growing rapidly on unlimited resources (Craig et al. 2006). In total these experimental results suggest the hypothesis that density-dependent competition for food and size-dependent predation are important in mediating the strength of density-dependent mortality of juvenile spot in the field.

To begin extrapolating our results to the field, we compared the densities at which effects on growth and mortality occurred in our experiments with those from published field studies (Fig. 6). Not surprisingly, spot densities were highest during the period of peak recruitment to benthic estuarine habitats (March to April), reaching densities well above those in our experiments. Densities were typically much lower later in the season (May to July), but often within the range in which growth and mortality were density-dependent $\left(<2\right.$ to 10 fish $\left.\mathrm{m}^{-2}\right)$. Given that the efficiency of gears used in these studies is typically low (trawls: 9 to $39 \%$, Loesch et al. 1976, Kjelson \& Johnson 1978; seines: 12 to $78 \%$, Kjelson \& Johnson 1978, Weinstein \& Davis 1980, Weinstein 1983; rotenone: 29 to $60 \%$, Weinstein \& Davis 1980), absolute spot densities were probably higher than those reported. These observations suggest that density-dependent effects on growth and mortality of juvenile spot in the field may occur over a relatively large portion of the summer growing season.

An important limitation of our experimental approach is the constraint that enclosures impose on the movements of fish that can potentially move rapidly

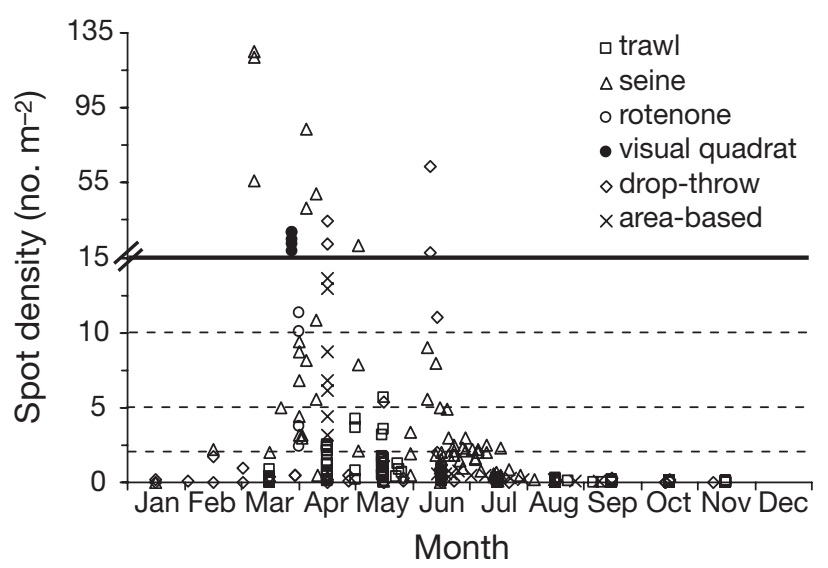

Fig. 6. Leiostomus xanthurus. Density estimates of juvenile spot in estuarine habitats reported or calculated from published field observations. Estimates not corrected for gear efficiency or selectivity. We assumed the midpoint of the sampling interval when exact sampling dates were not provided. Dashed lines: treatment densities $\left(2,5\right.$, and 10 fish $\left.\mathrm{m}^{-2}\right)$ at which effects on spot growth and mortality were observed in the experiments reported here. Note the difference in scale of the $y$-axis above and below the continuous line (15 fish $\mathrm{m}^{-2}$ ). Symbol designations correspond to gear types: densities based on drop nets, throw traps, and wegener rings were pooled as 'drop-throw', those based on channel nets (that sampled fish leaving a habitat with the tide) and mark-recapture methods were pooled as 'areabased'. Data from US Geographic locations - Virginia, $n=73$ : Weinstein (1983), Weinstein \& Brooks (1983), Weinstein et al. (1984), Weinstein \& O'Neil (1986); North Carolina, $\mathrm{n}=160$ : Adams (1976), Weinstein (1979), Rozas \& Hackney (1984), Ross \& Epperly (1985), Rulifson (1985), Ross (1992), Miltner et al. (1995), Stokesbury \& Ross (1997); Georgia, $\mathrm{n}=18$ : Rogers et al. (1984); Gulf coast, $\mathrm{n}=24$ : Loesch et al. (1976), Subrah-manyam \& Coultas (1980), Zimmerman \& Minello (1984) 
over large areas. Whether juvenile estuarine fishes emigrate in response to high density and intense intraspecific competition is unknown. Perhaps the density-dependent effects that we observed would have been alleviated if spot were able to move to alternative habitats. The similar effect of density between experiments differing by 2 orders of magnitude in spatial scale argues against this possibility. In addition, 2 independent tagging studies estimated the average residence time of juvenile spot in marsh nursery creeks to be 81 and $91 \mathrm{~d}$, with some fish resident for up to 162-182 d (Weinstein 1983, Weinstein et al. 1984), which is well beyond the duration over which density-dependent effects occurred in our experiments (51 to 52 d). Juveniles of other estuarydependent species also exhibit similar high site fidelity (Knudsen \& Herke 1978, Miller \& Able 2002, Pothoff \& Allen 2003). Therefore, it is not obvious a priori that density-dependent effects can always be mitigated simply by moving. Further, density-dependent emigration may be a mechanism leading to density-dependent growth and mortality if the habitats to which fish move are of lower quality (e.g. more predators, less food). Finally, while our experiments may have constrained the movements of spot, they also excluded predators and interspecific competitors that would typically impose additional energetic costs or demands on available food resources that would affect spot growth rates.

Concerns are growing about habitat degradation and the potential for estuarine nursery habitats to support the growth and survival of juvenile marine fishes (Beck et al. 2001). A recent study investigating variation in estuarine nursery habitat quality for juvenile spot and croaker assumed that growth and mortality were independent of density and considered estuaries to be generally undersaturated with juveniles of estuary-dependent fishes (Ross 2003). In contrast, we have found strong experimental evidence for density-dependent growth and mortality in juvenile spot within the range of field densities commonly reported in estuarine habitats. These results are consistent with a growing number of field studies indicating that density-dependent processes during the juvenile stage in estuaries may be important for a number of marine fishes (van der Veer 1986, McBride et al. 1995, Buckel et al. 1999, Kimmerer et al. 2000, Scharf 2000). Density-dependent effects should be considered in efforts to understand the factors underlying variation in the relative value of alternative nursery habitats for estuarine fishes. Process-oriented field studies are needed to further understand the role of density-dependence in driving the dynamics of spot and other estuary-dependent species.
Acknowledgements. We thank the University of North Carolina at Chapel Hill Institute of Marine Sciences for use of the ponds and R. Cheshire, L. Cowell, M. Crawford, K. Garner, H. Griffin, L. Heatherly, S. Little, B. McCollum, S. Nixon, J. Quinlan, D. Squires, and A. Whichard for help in conducting the experiments. D. Brady, J. Buckel, S. Luthy, F. Scharf, K. Stierhoff, C. Taylor and 3 anonymous reviewers provided useful discussion or comments on the manuscript. We thank the National Marine Fisheries Service Beaufort laboratory for access to fish holding facilities. This research was supported by the National Sea Grant College Program, National Oceanic and Atmospheric Administration (NOAA), and the University of North Carolina Sea Grant Program under grants NA90AA-D-SG062 (R/MER-24) and NA16RG2251 (R/MRD49) and by the North Carolina Agricultural Research Service. The views expressed herein are those of the authors and do not necessarily reflect the views of NOAA or any of its subagencies.

\section{LITERATURE CITED}

Adams SM (1976) The ecology of eelgrass, Zostera marina (L.), fish communities: structural analysis. J Exp Mar Biol Ecol 22:269-291

Anderson RO, Gutreuter SJ (1983) Length, weight, and associated structural indices. In: Nielsen LA, Johnson DL (eds) Fisheries techniques. Southern Printing Company, Blacksburg, VA, p 283-300

Beck MW, Heck KL, Able KW, Childers DL and 9 others (2001) The identification, conservation, and management of estuarine and marine nurseries for fish and invertebrates. Bioscience 51:633-641

Buckel JA, Conover DO, Steinberg ND, McKown KA (1999) Impact of Age-0 bluefish (Pomatomus saltatrix) predation on Age-0 fishes in the Hudson River estuary: evidence for density-dependent loss of juvenile striped bass (Morone saxatilis). Can J Fish Aquat Sci 56:275-287

Burnham KP, Anderson DR (2002) Model selection and multimodel inference: a practical information-theoretic approach, 2nd edn. Springer-Verlag, New York

Cowan JH, Rose KA, DeVries DR (2000) Is density-dependent growth in young-of-the-year fishes a question of critical weight? Rev Fish Biol Fish 10:61-89

Craig JK, Burke BJ, Crowder LB, Rice JA (2006) Prey growth and size-dependent predation in juvenile estuarine fishes: experimental and model analyses. Ecology 87: 2366-2377

Diaz RJ (2000) Overview of hypoxia around the world. J Environ Qual 30:275-281

Eby LA, Crowder LB, McClellan CM, Peterson CH, Powers MJ (2005) Habitat degradation from intermittent hypoxia: impacts on demersal fishes. Mar Ecol Prog Ser 291: $249-261$

Forrester GE, Steele MA (2000) Variation in the presence and cause of density-dependent mortality in three species of reef fishes. Ecology 81:2416-2427

Gibbard GL, Strawn K, Aldrich DV (1979) Feeding and aggressive behavior of Atlantic croaker, black drum, and striped mullet in monoculture and polyculture. Proc World Maricult Soc 10:241-248

Hixon MA, Jones GP (2005) Competition, predation, and density-dependent mortality in demersal marine fishes. Ecology 86:2847-2859

Hixon MA, Pacala SW, Sandin SA (2002) Population regulation: historical context and contemporary challenges in open vs. closed systems. Ecology 83:1490-1508 
Hodson RG, Hackman JO, Bennett CR (1981) Food habits of young spots in nursery areas of the Cape Fear estuary, North Carolina. Trans Am Fish Soc 110:495-501

Jenkins TM, Diehl S, Kratz KW, Cooper SD (1999) Effects of population density on individual growth of brown trout in streams. Ecology 80:941-956

Kimmerer WJ, Cowan JH, Miller LW, Rose KA (2000) Analysis of an estuarine striped bass (Morone saxatilis) population: influence of density-dependent mortality between metamorphosis and recruitment. Can J Fish Aquat Sci 57: 478-486

Kjelson MA, Johnson GN (1978) Catch efficiency of a 6.1meter otter trawl for estuarine fish populations. Trans Am Fish Soc 107:246-254

Knudsen EE, Herke WH (1978) Growth rate of marked juvenile Atlantic croakers, Micropogon undulatus, and length of stay in a coastal marsh nursery in southwest Louisiana. Trans Am Fish Soc 107:12-20

Langton SD, Aebischer NJ, Robertson PA (2002) The estimation of density dependence using census data from several sites. Oecologia 133:466-473

Leggett WC, DeBlois E (1994) Recruitment in marine fishes: is it regulated by starvation and predation in the egg and larval stages? Neth J Sea Res 32:119-134

Loesch J, Bishop J, Crowe A, Kuckyr R, Wagner P (1976) Technique for estimating trawl efficiency in catching brown shrimp (Penaeus aztecus), Atlantic croaker (Micropogon undulatus) and spot (Leiostomus xanthurus). Gulf Res Rep 5:29-33

Lorenzen K, Enberg K (2002) Density-dependent growth as a key mechanism in the regulation of fish populations: evidence from among-population comparison. Proc R Soc Lond B 269:49-54

McBride RS, Scherer MD, Powell JC (1995) Correlated variations in abundance, size, growth, and loss rates of Age-0 bluefish in a southern New England estuary. Trans Am Fish Soc 124:898-910

Miller MJ, Able KW (2002) Movements and growth of tagged young-of-the-year Atlantic croaker (Micropogonias undulatus) in relation to bottom salinity and temperature in South Carolina estuaries. Estuaries 5:216-223

Miltner RJ, Ross SW, Posey MH (1995) Influence of food and predation on the depth distribution of juvenile spot (Leiostomus xanthurus) in tidal nurseries. Can J Fish Aquat Sci 53:971-982

Modin J, Pihl L (1994) Differences in growth and mortality of juvenile plaice, Pleuronectes platessa L., following normal and extremely high settlement. Neth J Sea Res 32: 331-341

Myers RA, Cadigan NG (1993) Density-dependent juvenile mortality in marine demersal fish. Can J Fish Aquat Sci 50: 1576-1590

Potthoff MT, Allen DM (2003) Site fidelity, home range, and tidal migrations of juvenile pinfish, Lagodon rhomboides, in salt marsh creeks. Environ Biol Fish 67:231-240

Powers SP, Peterson CH, Christian RR, Sullivan E, Powers MJ, Bishop MJ, Buzzelli CP (2005) Effects of eutrophication on bottom habitat and prey resources of demersal fishes. Mar Ecol Prog Ser 302:233-243

Quinlan JA, Crowder LB (1999) Searching for sensitivity in the life history of Atlantic menhaden: inferences from a matrix model. Fish Oceanogr 8(Suppl 2):124-133

Ricker WE (1975) Computation and interpretation of biological statistics of fish populations. Bull Fish Res Board Can 191:1-382

Rogers SG, Targett TE, Van Sant SB (1984) Fish-nursery use in Georgia salt-marsh estuaries: the influence of spring- time freshwater conditions. Trans Am Fish Soc 113: 595-606

Ross SW (1992) Comparisons of population dynamics of juvenile spot, Leiostomus xanthurus, Atlantic croaker, Micropogonias undulatus, and Atlantic menhaden, Brevoortia tyrannus, among diverse North Carolina nursey areas. PhD dissertation, North Carolina State University, Raleigh, NC

Ross SW (2003) The relative value of different estuarine nursery areas in North Carolina for transient juvenile marine fishes. Fish Bull US Dep Comm 101:384-404

Ross SW, Epperly SP (1985) Utilization of shallow estuarine nursery areas by fishes in Pamlico Sound and adjacent tributaries, North Carolina. In: Yáñez-Arancibia (ed) Fish community ecology in estuaries and coastal lagoons: towards ecosystem integration. DR(R) Unam Press, Mexico City p 207-232

Rozas LB, Hackney CT (1984) Use of oligohaline marshes by fishes and macrofaunal crustaceans in North Carolina. Estuaries 7:213-224

Rubenstein DI (1981) Individual variation and competition in the Everglades pygmy sunfish. J Anim Ecol 50:337-350

Rulifson RA (1985) Distribution and abundance of fishes in tributaries of South Creek estuary, North Carolina. J Elisha Mitchell Sci Soc 101:160-176

Scharf FS (2000) Patterns of abundance, growth, and mortality of juvenile red drum across estuaries on the Texas coast with implications for recruitment and stock enhancement. Trans Am Fish Soc 129:1207-1222

Sheridan PF (1979) Trophic resource utilization by three species of sciaenid fishes in a northwest Florida estuary. Northeast Gulf Sci 3:1-15

Sissenwine MP (1984) Why do fish populations vary? In: May RM (ed) Exploitation of marine communities. SpringerVerlag, Berlin, p 59-64

Sogard SM (1997) Size-selective mortality in the juvenile stage of teleost fishes: a review. Bull Mar Sci 60:1129-1157

Stickney RR, Taylor GL, White DB (1975) Food habits of five species of young southeastern United States estuarine Sciaenidae. Chesapeake Sci 16:104-114

Stokesbury KDE, Ross SW (1997) Spatial distribution and an absolute density estimate of juvenile spot Leiostomus xanthurus in the tidal fringe bordering a North Carolina salt marsh. Mar Ecol Prog Ser 149:289-294

Subrahmanyam CB, Coultas CL (1980) Studies on the animal communities in two North Florida salt marshes. Part III. Seasonal fluctuations of fish and macroinvertebrates. Bull Mar Sci 30:790-818

van der Veer HW (1986) Immigration, settlement, and density-dependent mortality of a larval and early postlarval 0-group plaice (Pleuronectes platessa) population in the western Wadden Sea. Mar Ecol Prog Ser 29:223-236

Walters CJ, Post JR (1993) Density-dependent growth and competitive asymmetries in size-structured fish populations: a theoretical model and recommendations for field experiments. Trans Am Fish Soc 122:34-45

Weinstein MP (1979) Shallow marsh habitats as primary nurseries for fishes and shellfish, Cape Fear River, North Carolina. Fish Bull US Dep Comm 77:339-357

Weinstein MP (1983) Population dynamics of an estuarinedependent fish, the spot (Leiostomus xanthurus), along a tidal creek-seagrass meadow coenocline. Can J Fish Aquat Sci 40:1633-1638

Weinstein MP, Brooks HA (1983) Comparative ecology of nekton residing in a tidal creek and adjacent seagrass meadow: community composition and structure. Mar Ecol Prog Ser 12:15-27 
Weinstein MP, Davis RW (1980) Collection efficiency of seine and rotenone samples from tidal creeks, Cape Fear River, North Carolina. Estuaries 3:98-105

Weinstein MP, O'Neil SP (1986) Exchange of marked juvenile spots between adjacent tidal creeks in the York River estuary, Virginia. Trans Am Fish Soc 115:93-97

Weinstein MP, Scott L, O'Neil SP, Siegfried RC, Szedlmayer ST (1984) Population dynamics of spot, Leiostomus xanthurus, in polyhaline tidal creeks of the York River estuary, Virginia. Estuaries 7:444-450

Wright RA, Crowder LB, Martin TH (1993) The effects of predation on the survival and size-distribution of estuarine

Editorial responsibility: Jon Hare (Contributing Editor),

Narragansett, Rhode Island, USA fishes: an experimental approach. Environ Biol Fish 36: 291-300

Yip-Hoi TA (2003) An investigation of effects of dissolved oxygen level, sediment type, stocking density, and predation on the growth rate, survivorship, and burrowing behavior of juvenile brown and white shrimp. PhD dissertation, North Carolina State University, Raleigh, NC

Zar JH (1996) Biostatistical analysis, 3rd edn. Prentice Hall, Upper Saddle River, NJ

Zimmerman RJ, Minello TJ (1984) Densities of Penaeus aztecus, Penaeus setiferus, and other natant macrofauna in a Texas salt marsh. Estuaries 7:421-433

Submitted: July 9, 2006; Accepted: December 18, 2006 Proofs received from author(s): July 23, 2007 